\title{
Effect of extended postmortem aging and steak location on myofibrillar protein degradation and Warner-Bratzler shear force of beef $M$. semitendinosus steaks ${ }^{1}$
}

\author{
K. J. Phelps, J. S. Drouillard, M. B. Silva, L. D. F. Miranda, \\ S. M. Ebarb, C. L. Van Bibber-Krueger, T. G. O'Quinn, and J. M. Gonzalez ${ }^{2}$ \\ Department of Animal Sciences and Industry, Kansas State University, Manhattan 66506
}

\begin{abstract}
The objective of this study was to evaluate the effect of steak location and postmortem aging on cooked meat tenderness and myofibrillar protein degradation of steaks from M. semitendinosus (ST). Following harvest and a $6 \mathrm{~d}$ chill period, the left ST was removed from carcasses of crossbred feedlot steers ( $n=$ 60 , average hot carcass weight $427 \pm 24 \mathrm{~kg}$ ). Each ST was fabricated into ten 2.54 -cm thick steaks originating from the proximal to distal end of the muscle. Steaks cut adjacent to each other were paired, vacuum packaged, and randomly assigned to $7,14,21,42$, or $70 \mathrm{~d}$ of aging at $2 \pm 1{ }^{\circ} \mathrm{C}$. After aging, within each steak pair, steaks were randomly assigned to Warner-Bratzler shear force or myofibrillar proteolysis analysis (calpain activity and desmin and troponin-T degradation). Muscle fiber type and size were also determined at the 2 ends of the muscle. There was no location $\times \mathrm{d}$ of aging interaction $(P=0.25)$ for ST steak WBSF. Steak location affected (quadratic, $P<0.01$ ) WBSF. As steaks were fabricated from the proximal to distal end, WBSF values decreased toward the middle of the muscle and then increased toward the distal end. Activity of all calpains and myofibrillar protein proteolysis were unaffected by
\end{abstract}

steak location $(P>0.13)$. Type I, IIA, and IIX muscle fibers were larger at the proximal end of the muscle than the distal end $(P<0.01)$. Increasing $d$ of aging improved WBSF (quadratic, $P<0.01$ ) for the duration of the $70 \mathrm{~d}$ postmortem period. As $\mathrm{d}$ of aging increased, intact calpain- 1 activity decreased (quadratic, $P<0.01$ ) with activity detected through $42 \mathrm{~d}$. Day of aging affected autolyzed calpain-1 (linear, $P<0.01$ ) and calpain-2 activity (quadratic, $P<0.01$ ). Through d 70 of aging, the intensity of intact $55 \mathrm{kDa}$ desmin band decreased (linear, $P<0.01$ ), while there was an increase (linear, $P<0.01)$ in the degraded $38 \mathrm{kDa}$ band. Similarly, $\mathrm{d}$ of aging increased troponin-T proteolysis, indicated by a decrease (quadratic, $P<0.01$ ) in intensity of the intact $40 \mathrm{kDa}$ band and an increase (linear, $P<0.01$ ) in the $30 \mathrm{kDa}$ degraded band. Intramuscular WBSF differences are not due to proteolytic activity or myofibrillar degradation and seem related to muscle fiber size. The improvement of ST steak WBSF through $70 \mathrm{~d}$ of aging is partly due to continued degradation of desmin and troponin-T. Calpain proteolytic analysis indicates that autolyzed calpain-1 and calpain-2 may be involved in extended postmortem myofibrillar protein proteolysis.

Key words: Extended aging, location, M. semitendinosus, tenderness, calpain

(C) 2016 American Society of Animal Science. All rights reserved.

\section{INTRODUCTION}

Beef tenderness is the most important trait affecting consumer beef-eating satisfaction (Beermann, 2009). Lusk et al. (2001) found $51 \%$ of consumers were willing to pay a premium of $\$ 1.84$ more per

\footnotetext{
${ }^{1}$ Contribution No. 16-107-J of the Kansas Agricultural Experiment Station, Manhattan, KS 66506.

${ }^{2}$ Corresponding author: johngonz@k-state.edu

Received September 14, 2015.

Accepted October 16, 2015.
}

J. Anim. Sci. 2016.94:412-423 doi: 10.2527/jas2015-9862

$0.45 \mathrm{~kg}$ for beef that carried a tenderness guarantee. Tenderness is often only measured in muscles arising from the rib and loin because of their high economic value. With recent record high beef prices, there is a need to identify more economical cuts that will meet consumer expectations for tenderness.

Several researchers have previously examined tenderness across different locations of the M. semitendinosus (ST; Shackelford et al., 1997; Rhee et al., 2004; Von Seggern et al., 2005; Senaratne et al., 2010), but in these studies tenderness was only measured at one aging time point. Despite its large connective 
tissue content (Light et al., 1985), the ST moderately responds to aging after $28 \mathrm{~d}$ according the Industry Guide for Beef Aging (CCB, 2006), improving shear force values by 1.4 and $1.6 \mathrm{~kg}$ for USDA Choice and USDA Select grade muscles, respectively. Retail steaks from this muscle receive, on average, $17 \mathrm{~d}$ of aging, with almost half receiving less than $14 \mathrm{~d}$ (Guelker et al., 2013); this indicates an opportunity to examine how extended postmortem aging impacts tenderness of the ST.

Since the early $1900 \mathrm{~s}$, literature has demonstrated that meat tenderness improves with postmortem storage at refrigerated temperatures (Lehman, 1907). During postmortem storage, connective tissue may be weakened, but this ultimately has no effect on tenderness (Purslow, 2005). Hence, the extent of tenderization is dependent on factors including sample location, aging time, and the extent of myofibrillar protein degradation caused by enzymatic activity of the calpain system (Koohmaraie and Geesink, 2006). Therefore, the objective of this study was to evaluate the effect of steak location and postmortem aging up to $70 \mathrm{~d}$ on cooked meat tenderness and myofibrillar protein degradation of steaks from the ST.

\section{MATERIALS AND METHODS}

\section{Animals and M. semitendinosus Collection}

Sixty black-hided crossbred feedlot steers were purchased at an auction barn in Kansas for finishing at the Kansas State University Beef Cattle Research Center. After finishing, steers were harvested at a commercial abattoir (Creekstone Farms, Arkansas City, KS) at approximately 18 mo of age. The final BW and hot carcass weight of the steers were $691 \pm$ $37 \mathrm{~kg}$ and $427 \pm 24 \mathrm{~kg}$, respectively. Following a $6 \mathrm{~d}$ chilling period, the ST was removed from the left side of each carcass and transported under refrigeration to the Kansas State University Meats Laboratory.

\section{M. semitendinosus Processing}

Before steak fabrication, the distal and proximal portions of the muscle that were not large enough to yield a steak were removed for immunohistochemical analysis. Each ST was fabricated into 10, 2.54-cm thick steaks with steak 1 being more proximal and steak 10 being more distal to the steer's body. Adjacent steaks were paired (1 and 2, 3 and 4, etc.), vacuum-packaged, and randomly assigned to $7,14,21,42$, or $70 \mathrm{~d}$ of aging. All roasts were aged at $2 \pm 1^{\circ} \mathrm{C}$ with temperature monitored using a Thermochron iButton (Maxim Integrated Products, Sunnyvale, CA). Following each aging period, 1 steak was utilized for objective measurement of tenderness using Warner-Bratzler shear force (WBSF) and 1 steak was cubed into $1.27 \times 1.27 \times 1.27 \mathrm{~cm}$ pieces and frozen at $-80^{\circ} \mathrm{C}$ for laboratory analysis.

\section{Warner-Bratzler Shear Force}

Warner-Bratzler shear force procedures were conducted according to the American Meat Science Association (AMSA) Meat Cookery and Sensory Guidelines (AMSA, 2015). Before cooking, a thermocouple wire (30-gauge copper and constantan; Omega Engineering, Stamford, CT) was inserted into the geometric center of each steak for internal temperature monitoring using a Doric Minitrend 205 monitor (VAS Engineering, San Francisco, CA). Steaks were cooked to an internal temperature of $71^{\circ} \mathrm{C}$ on clamstyle grills (Cuisinart Griddler; Cuisinart, Stamford, CT) set to $232^{\circ} \mathrm{C}$. Following a 24 -h chill period at $2 \pm 1{ }^{\circ} \mathrm{C}$, six 1.27 -cm cores were removed parallel to the muscle fiber orientation and were sheared once through the center using an Instron testing machine (Model 5569; Instron, Canton, MA) with a WarnerBratzler shear head attached (100 kg compression load cell and crosshead speed of $250 \mathrm{~mm} / \mathrm{min}$ ).

\section{Sarcoplasmic Protein Extraction}

Samples for casein zymography were extracted using procedures previously described by Shackelford et al. (1994) with the following modifications. A finely minced 5 -g tissue sample was homogenized in $3 \mathrm{vol}$ (wt/vol) of extraction buffer containing $100 \mathrm{mM}$ Tris- $\mathrm{HCl}(\mathrm{pH}$ 8.3), $10 \mathrm{~m} M$ EDTA, $0.1 \%$ (vol/vol) $\beta$-mercaptoethanol (MCE), $2 \mathrm{~m} M$ phenylmethylsulfonylfluoride, and $1.5 \mu \mathrm{L}$ of Protease Inhibitor Cocktail (P8340; Sigma Aldrich, St. Louis, MO). The resulting homogenate was centrifuged at $18,500 \times \mathrm{g}$ for $30 \mathrm{~min}$ at $4^{\circ} \mathrm{C}$. The supernatant was filtered through 3 layers of cheesecloth and the protein content of each sample was quantified using a Pierce BCA Protein Assay Kit (Thermo Scientific, Waltham, MA).

\section{Casein Zymography}

Differences in calpain activity were determined using casein zymography procedures described by Melody et al. (2004). One volume of supernatant from sarcoplasmic protein extraction was combined with 1 vol of loading dye solution (20\% glycerol, $0.75 \%$ [vol $/ \mathrm{vol}]$ MCE, $0.1 \%$ [wt/vol] bromophenol blue, and $150 \mathrm{mM}$ Tris-HCl, pH 6.8]) for a final sample concentration of 140 $\mu \mathrm{g} / \mu \mathrm{L}$. Samples were loaded onto $12.5 \%$ nondenaturing polyacrylamide gel electrophoresis (PAGE) casein gels (separating gel = acrylamide: N,N'-bis-methylene acrylamide $=100: 1[\mathrm{wt} / \mathrm{wt}], 0.05 \%[\mathrm{vol} / \mathrm{vol}] \mathrm{N}$ 'N'N'N'tetramethlyethylendediamine [TEMED], 0.05\% [wt/vol] 
a)

Intact calpain-1

Autolyzed calpain-1

Intact calpain-2

Intact desmin- $55 \mathrm{kDa}$

b)

Degraded desmin- $38 \mathrm{kDa}$

Intact troponin-T-40 kDa

c)

Degraded troponin-T- $30 \mathrm{kDa}$
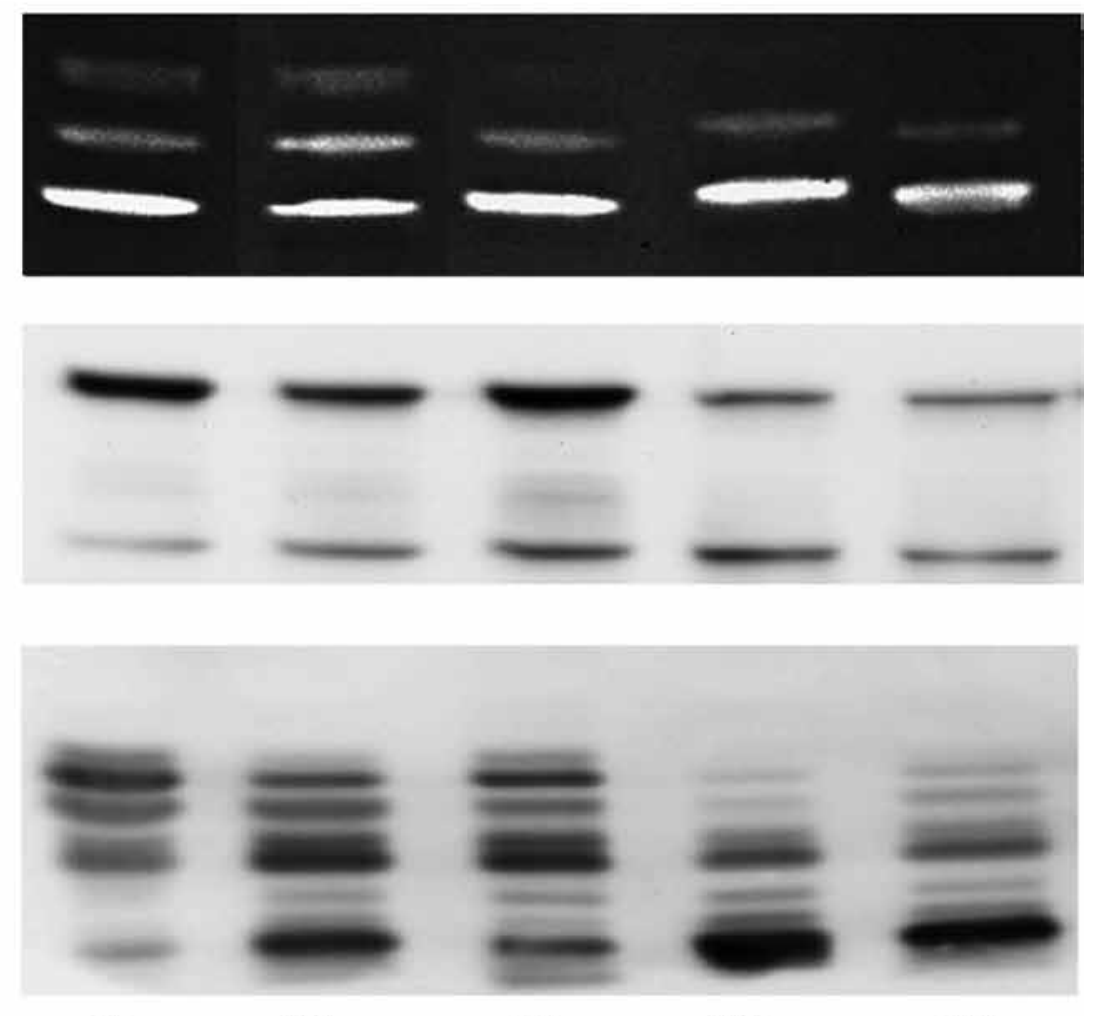

d7

d14

d21

d42

d70

Figure 1. Representative images of calpain zymogram (a), desmin immunoblot (b), and troponin-T immunoblot (c). Images encompass one steer's M. semitendinosus steaks aged for 7, 14, 21, 42, or $70 \mathrm{~d}$ postmortem.

ammonium persulfate [APS], casein $[2.1 \mathrm{mg} / \mathrm{mL}]$, and $375 \mathrm{~m} M$ Tris $\cdot \mathrm{HCl}, \mathrm{pH} 8.8$; stacking gel = acrylamide: N,N'-bis-methylene acrylamide $=100: 1$ [wt/wt], 0.125\% [vol $/ \mathrm{vol}]$ TEMED, $0.075 \%$ [wt/vol] APS, and $125 \mathrm{mM}$ Tris $\cdot \mathrm{HCl}, \mathrm{pH}$ 6.8). Proteins were separated on gels $(8 \mathrm{~cm}$ wide $\times 10 \mathrm{~cm}$ tall) using a SE 260 Hoefer Mighty Small II electrophoresis unit (Hoefer Scientific Instruments, San Francisco, CA). The running buffer consisted of $192 \mathrm{mM}$ glycine, $25 \mathrm{~m} M$ Tris-HCl, $1 \mathrm{~m} M$ EDTA, and $0.5 \%$ (vol/ vol) MCE, $\mathrm{pH} 8.3$. Gels were prerun at $100 \mathrm{~V}$ for $15 \mathrm{~min}$ and samples were separated at a constant voltage of 125 $\mathrm{V}$ for approximately $3 \mathrm{~h}$ and washed 3 times for $20 \mathrm{~min}$ in a buffer containing $50 \mathrm{mM}$ Tris $\cdot \mathrm{HCl}, 5 \mathrm{mM} \mathrm{CaCl}{ }_{2}$, and $0.1 \%$ (vol/vol) MCE, $\mathrm{pH} 7.5$. After $20 \mathrm{~h}$ of incubation in the same buffer solution at room temperature, gels were stained with a solution containing $0.1 \%(\mathrm{wt} / \mathrm{vol})$ Coomassie Brilliant Blue R-250, 40\% (vol/vol) methanol, and $7 \%$ (vol/vol) glacial acetic acid for $1 \mathrm{~h}$. Gels were destained using $40 \%$ (vol $/ \mathrm{vol})$ methanol and $7 \%$ (vol $/ \mathrm{vol})$ glacial acetic acid for $45 \mathrm{~min}$. Once destained, gels were imaged using a ChemiDoc-It 415 Imaging System (UVP, Upland, CA). Calpain activity (calpain-1, autolyzed calpain-1, and calpain-2) was determined by cleared bands in the stained gel (Fig. 1a). Band intensities were quantified using VisionWorksLS Image Acquisition and Analysis Software (UVP) and intensities of individual calpains were added to yield total calpain activity.

\section{Desmin and Troponin-T Western-Blot Analysis}

Sample preparation for analysis of desmin and troponin-T (TnT) was conducted as described by HuffLonergan et al. (1996) and Lonergan et al. (2001). Briefly, $0.2 \mathrm{~g}$ of the sample was homogenized in $5 \mathrm{~mL}$ of whole muscle protein extraction buffer (10 $\mathrm{m} M$ sodium phosphate and $2 \% \mathrm{SDS}, \mathrm{pH} 7.0$ ). The homogenate was centrifuged at $1,500 \times \mathrm{g}$ for $15 \mathrm{~min}$ at $20^{\circ} \mathrm{C}$. Protein concentration of the samples was quantified using a Pierce BCA Protein Assay Kit (Thermo Scientific). Samples were mixed with sample loading/tracking dye $(30 \mathrm{mM}$ Tris-HCl, pH 8.0, 3 mM EDTA, 20\% [vol/vol] glycerol, $3 \%$ [wt/vol] SDS, $0.003 \%$ [wt/vol] bromophenol blue) and 45 and $30 \mu \mathrm{g}$ of desmin and TnT, respectively, were loaded onto separate $10 \%$ polyacrylamide separating gels (acrylamide:N,N'-bis-methylene acrylamide $=100: 1$ [wt/wt], 0.1\% [wt/vol] SDS, 0.05\% [vol/vol] TEMED, $0.05 \%$ [wt/vol] APS, and $0.5 \mathrm{M}$ Tris-HCl, $\mathrm{pH} 8.8$ ) with a $5 \%$ polyacrylamide stacking gel (acrylamide: $\mathrm{N} \mathrm{N}^{\prime}$-bismethelyene acrylamide $=100: 1[\mathrm{wt} / \mathrm{wt}], 0.1 \%[\mathrm{wt} / \mathrm{vol}]$ SDS, $0.125 \%$ [vol/vol] TEMED, 0.075\% [wt/vol] APS, and $0.125 M$ Tris-HCl, $\mathrm{pH}$ 6.8). Proteins were separated as described above at a constant amperage (40 mA). The running buffer used contained $25 \mathrm{~m} M$ Tris, $192 \mathrm{~m} M$ glycine, $2 \mathrm{~m} M$ EDTA, and $0.1 \%$ (wt/vol) SDS. Following electrophoresis, proteins were transferred to nitrocellulose membranes (Amersham Hybond-ECL; GE 
Healthcare Bio-Sciences, Pittsburgh, PA) using a TE77X Semi-dry Transfer Unit (Hoefer) at a constant amperage $(140 \mathrm{~mA})$ for $1.5 \mathrm{~h}$. The transfer buffer used contained 25 $\mathrm{m} M$ Tris, $192 \mathrm{~m} M$ glycine, $2 \mathrm{~m} M$ EDTA, and 15\% (vol/ vol) methanol. After transfer, membranes were stained with Ponceau-S to verify equal loading.

Membranes were blocked with 5\% non-fat dry milk (NFDM) diluted in $10 \mathrm{mM}$ Tris, $\mathrm{pH} 8.0,150 \mathrm{mM}$ $\mathrm{NaCl}, 0.1 \%$ Tween-20 (TBS-T) for $30 \mathrm{~min}$ at room temperature to block non-specific antigen binding sites. Subsequently, desmin blots were incubated for $20 \mathrm{~h}$ at $4^{\circ} \mathrm{C}$ with a whole rabbit antiserum antidesmin antibody (D8281; Sigma Aldrich) diluted 1:15,000 in 1\% NFDM and TBS-T. Troponin-T blots were incubated for $20 \mathrm{~h}$ at $4^{\circ} \mathrm{C}$ with a mouse monoclonal antitroponin-T antibody (T6277; Sigma Aldrich) diluted 1:30,000 in 5\% NFDM and TBS-T. After incubation and washing 3 times for 5 min in TBS-T, desmin blots were incubated with an antirabbit, horseradish peroxidase (HRP) linked secondary antibody (7074; Cell Signaling Technology, Danvers, MA) diluted 1:20,000 in 5\% NFDM and TBS-T for 1 $\mathrm{h}$ at room temperature. Troponin-T blots were incubated with an antimouse, HRP-linked secondary antibody (7076; Cell Signaling Technology) diluted 1:20,000 in 5\% NFDM and TBS-T for $1 \mathrm{~h}$ at room temperature. After washing as described above, membranes were developed using an enhanced chemiluminescence kit (ECL Plus; GE Healthcare Bio-Sciences) and imaged using a ChemiDoc-It 415 Imaging System (UVP, Upland, CA). Band intensities were measured using VisionWorksLS Image Acquisition and Analysis Software (UVP). Intact and degraded forms of desmin measured were immunoreactive bands located at $55 \mathrm{kDa}$ and $38 \mathrm{kDa}$, respectively (Fig. 1b). Intact and degraded forms of TnT measured were immunoreactive bands located at 40 and $30 \mathrm{kDa}$, respectively (Fig. 1c). Bands were equalized to a pooled sample on each blot.

\section{Immunohistochemistry}

The methods of Phelps et al. (2014) were followed for immunohistochemical analysis. A $1 \mathrm{~cm} \times 1 \mathrm{~cm} \times 1$ $\mathrm{cm}$ sample was collected from the center of the steaks removed from the most distal and proximal location of the ST and frozen in tissue freezing medium. Ten micrometer cryosections were collected and blocked with $10 \%$ horse serum and $0.2 \%$ TritonX-100 in PBS. Cryosections were then incubated with the following primary antibodies for 1 h 1:500 rabbit $\alpha$-dystrophin (catalog \#PA1-37587; Thermo Scientific, Waltman, MA), 1:10 supernatant mouse anti-MHC, slow, IgG2b (BA-D5; Developmental Studies Hybridoma Bank, University of Iowa, Iowa City, IA), and 1:10 mouse anti-MHC all but type IIX, IgG1 (BF-35; Developmental Studies Hybridoma Bank). After washing with PBS, sections were incubated with the following secondary antibodies for $30 \mathrm{~min}$ : goat antimouse IgG1 Alexa-Fluor 488, goat antimouse IgG2 Alexa Fluor 633, and goat antirabbit H \& L Alexa Fluor 594 (Invitrogen, Grand Island, NY). After a final wash with PBS, slides were cover-slipped and photomicrographs were captured using a Nikon Eclipse TI-U inverted microscope equipped with a DS-QiMC digital camera at a $10 \times$ working distance magnification (Nikon Instruments Inc., Melville, NY). Photomicrographs were analyzed for MHC type distribution and individual muscle fiber cross-sectional area (CSA) using NIS-Elements Imaging Software (Basic Research, 3.3; Nikon Instruments, Inc.). For each steak location, a minimum of 500 fibers and 2 photomicrographs were analyzed. The area constrained by $\alpha$-dystrophin immunostaining defined individual fibers for CSA measurements. Fibers that stained positive for the BA-D5 antibody were classified as type I fibers. Fibers that stained positive for BF-35 but that were negative for BA-D5 were classified as type IIA fibers. All fibers that were negative for both BA-D5 and BF-35 antibodies were classified as type IIX fibers (MorenoSanchez et al., 2008; Schiaffino et al., 1989).

\section{Statistical Analysis}

Data were analyzed as a randomized complete block design with $5 \times 10$ factorial arrangement using the PROC MIXED procedure of SAS 9.4 (SAS Inst. Inc., Cary, NC). Day of aging (DOA), location (LOC), and their interaction served as fixed effects and weight block of the animal from which the muscle was harvested served as a random effect. Preplanned linear and quadratic contrasts for DOA and LOC were tested for all data. Differences were considered significant at $P \leq 0.05$.

\section{RESULTS}

\section{Warner-Bratzler Shear Force}

There was no LOC $\times$ DOA interaction for ST steak WBSF $(P=0.25)$. Steak LOC affected (quadratic, $P<$ $0.01)$ WBSF values. As steaks were fabricated from the proximal to distal end of the ST, WBSF values decreased toward the middle and then increased once again at the distal end (Fig. 2a). As DOA increased, WBSF decreased (Fig. 2b; quadratic, $P=0.02$ ), with the rate of decline being greater at the beginning of aging (up to $\mathrm{d} 21$ ) and slowing as $\mathrm{d} 70$ was reached.

\section{Calpain Activity}

There were no LOC $\times$ DOA interactions for calpain-1, autolyzed calpain-1, or calpain-2 activity $(P=$ 
0.26). Steak LOC had no impact on intact calpain-1, autolyzed calpain-1, intact calpain-2, or total calpain activities (Fig. 3a; $P>0.13$ ). As DOA increased, intact calpain-1 activity decreased (Fig. 3b; quadratic, $P<$ 0.01 ), with activity only detected up to $42 \mathrm{~d}$ postmortem. Day of aging also affected autolyzed calpain-1 (linear, $P<0.01$ ), intact calpain-2 (quadratic, $P<$ 0.01 ), and total calpain (quadratic, $P=0.02$ ) activities.

\section{Desmin and Troponin-T Degradation}

There were no LOC $\times$ DOA interactions for the relative band intensities of intact or degraded desmin and TnT $(P>0.19)$. Steak LOC did not affect intact or degraded desmin (Fig. 4) and TnT (Fig. 5) relative band densities $(P>0.14)$. The relative band density of intact desmin and TnT decreased (linear and quadratic, respectively, $P<0.01$ ) as DOA increased, while the relative band density of degraded desmin and TnT increased (linear, $P<0.01$ ). Band intensities of degraded desmin (Fig. 6a) and TnT (Fig. 6b) increased as DOA increased (linear, $P<0.01$ ).

\section{Muscle Fiber Type Distribution and Cross-Sectional Area}

There were differences in the muscle fiber type distribution and cross-sectional area between the 2 locations for all 3 fiber types. The proximal location possessed less type I and IIA fibers $(P<0.01)$ and more $(P<0.01)$ type IIX fibers than the distal location (Fig. 7a). Type I, IIA, and IIX fiber CSA were larger in the proximal portion of the ST when compared to the distal portion (Fig. $7 \mathrm{~b} ; P<0.01$ ).

\section{DISCUSSION}

Tenderness, juiciness, and flavor are the 3 main attributes consumers use to evaluate a beef eating experience (Miller et al., 2001). Tenderness is the most important attribute, and because of this, consumers are willing to pay more for products that carry a tenderness guarantee label (Lusk et al., 2001; Igo et al., 2013). Tenderization of the M. longissimus dorsi is well documented (Kerth et al., 2002; Rhee et al., 2004; Derington et al., 2011), but there is a need for a better understanding of tenderization patterns of underutilized beef cuts. Tenderness of muscles originating from the round, including the ST have been reported previously (Shackelford et al., 1997; Reuter et al., 2002; Rhee et al., 2004; Von Seggern et al., 2005; Senaratne et al., 2010); however, these data were collected at one aging time and often do not include mechanistic data. The ST is marketed at a reduced price $(\$ 6.65 / \mathrm{kg})$ compared to strip loins $(\$ 13.09 / \mathrm{kg})$ because

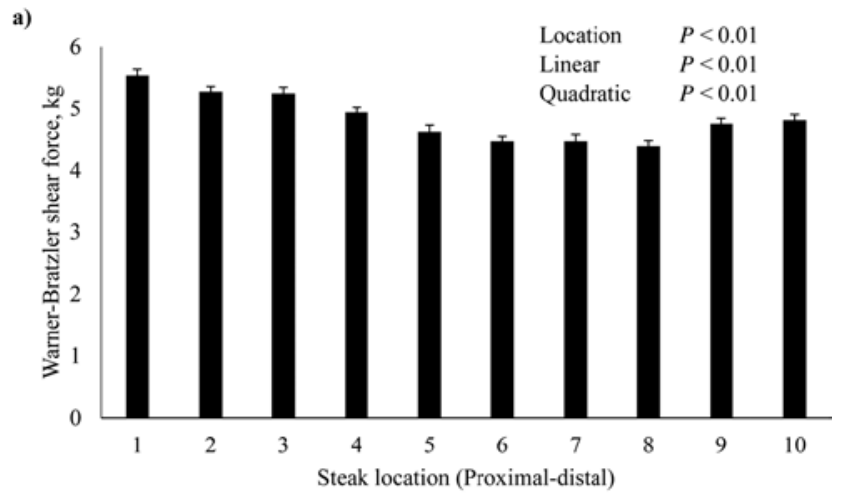

b)

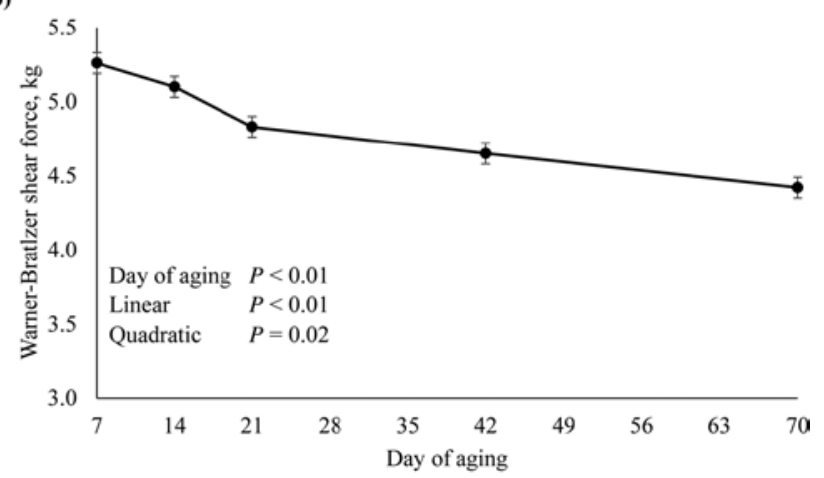

Figure 2. Effect of steak location (a) and postmortem aging time (b) on Warner-Bratzler shear force of steaks fabricated from 10 distinct locations of the M. semitendinosus. Steak 1 is the most proximal to the carcass and steak 10 is the most distal to the carcass and steaks were aged 7,14, 21,42 , or $70 \mathrm{~d}$ postmortem.

it is inherently tough; therefore, there is limited research examining tenderization mechanisms of this muscle. A better understanding of how tenderness can be improved in the ST may lead to alternative strategies to age and market this muscle to consumers.

In the most recent Beef Tenderness Survey, Guelker et al. (2013) reported the ST is aged on average $17 \mathrm{~d}$, but almost $50 \%$ of ST steaks receive less aging time. The current study examined how extended postmortem aging impacted tenderness of the ST. The quadratic effect detected for DOA indicated that the majority of improvement in WBSF occurred during the first $21 \mathrm{~d}$ of aging, but smaller improvements were achieved through d 70 postmortem. Shear force improved by $3.3 \%$ between 7 and 14 DOA, 5.9\% between 14 and 21 DOA, 3.2\% between 21 and 42 DOA, and 5.9\% between 42 and 70 DOA. Overall, there was $18.3 \%$ total improvement in shear force from $\mathrm{d} 7$ to 70 which resulted in an average shear force of $4.4 \mathrm{~kg}$ on $\mathrm{d} 70$. This is the WBSF value required for the current USDA Certified Tender program (ASTM, 2011). Gruber et al. (2006) reported ST steak d 28 shear force values that were similar to the $\mathrm{d} 70$ values reported in this study. The ability of the authors to achieve this level of tenderness more quickly may be due to steaks being cooked after being frozen and thawed, while in the current study steaks were cooked fresh. Juarez et al. (2010) 


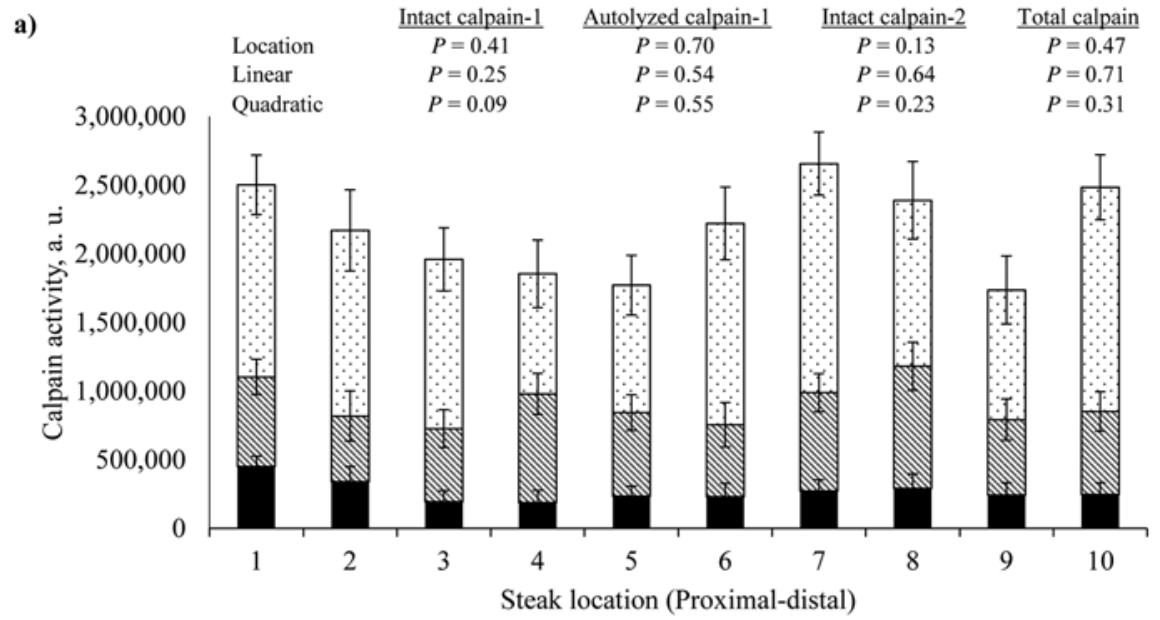

b)

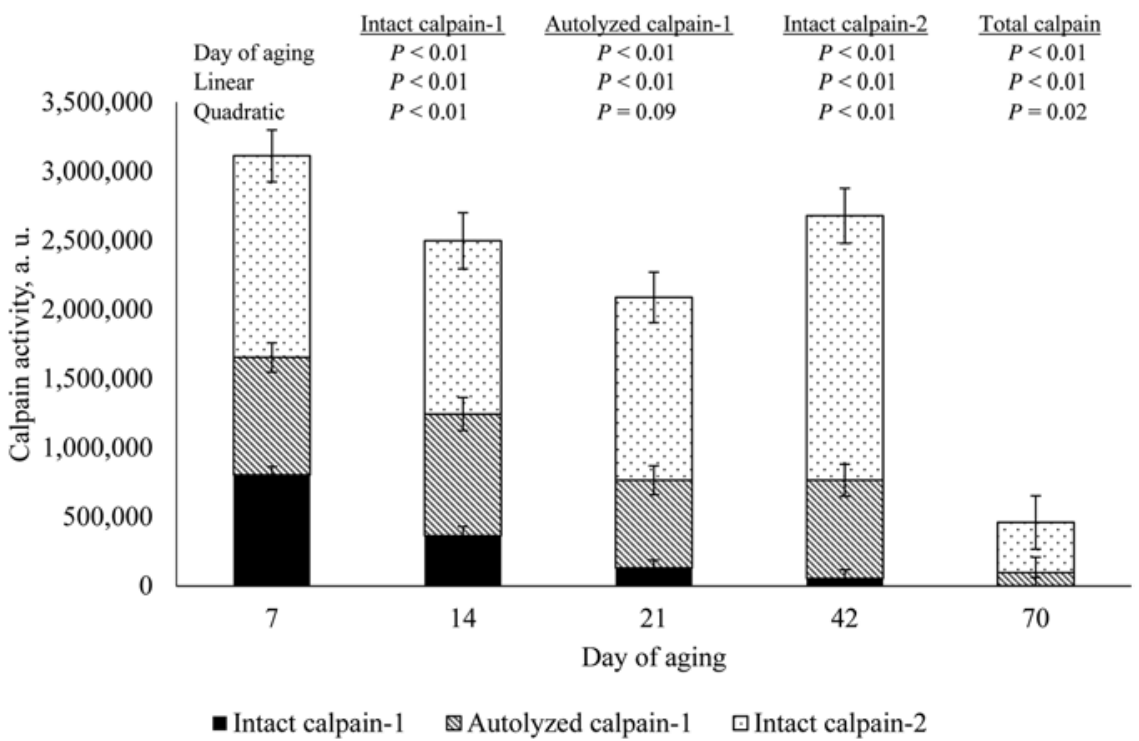

Figure 3. Effect of steak location (a) and postmortem aging time (b) on calpain-1, autolyzed calpain-1, and calpain-2 activity of steaks fabricated from 10 distinct locations of the M. semitendinosus. Steak 1 is the most proximal to the carcass and steak 10 is the most distal to the carcass and steaks were aged $7,14,21,42$, or $70 \mathrm{~d}$ postmortem.

did not detect improvements in ST steak tenderness past $28 \mathrm{~d}$ of a $56 \mathrm{~d}$ aging study. The authors reported a slight improvement in shear force of $1.7 \%$ between 7 and 14 DOA, a similar shear force improvement to the current study of $7.6 \%$ from 14 to 21 DOA.

In a similar manner to the increases in tenderness demonstrated, degradation of desmin and TnT continued through $\mathrm{d} 70$ of aging. The quadratic disappearance of the intact TnT band would indicate that the degradation of this protein was slowing as DOA advanced. In contrast, intact desmin disappeared in a linear fashion, indicating a constant rate of degradation. Huff-Lonergan et al. (1996) reported both desmin and TnT continued to be degraded through $56 \mathrm{~d}$ postmortem in M. longissimus thoracis steaks. Geesink and Koohmaraie (1999b) reported lamb M. biceps femoris desmin completely degraded by d 21 postmortem; however, TnT continued to degrade through d 56 postmortem. In Polodian (beef)
ST, Marino et al. (2015) reported degradation of both desmin and TnT through $21 \mathrm{~d}$ with almost all of the intact TnT band completely absent in samples. Therefore, there seems to be species, breed, and/or muscle differences in the degradation pattern of these 2 proteins.

There is substantial evidence indicating improvement in tenderness during postmortem aging is due to myofibrillar degradation caused by endogenous skeletal muscle proteases (Dransfield, 1994; Koohmaraie, 1994; Sentandreu et al., 2002; Koohmaraie and Geesink, 2006; Ouali et al., 2006; Huff-Lonergan et al., 2010; Kemp et al., 2010). Although there are several endogenous proteases, the calpain proteolytic system, especially calpain-1, is commonly reported to be responsible for the majority of postmortem degradation (Koohmaraie, 1992b; HuffLonergan et al., 1996). Calpain-1 is activated by the release of $\mathrm{Ca}^{2+}$ from the sarcoplasmic reticulum within the muscle cell postmortem and degrades several proteins in- 
a)

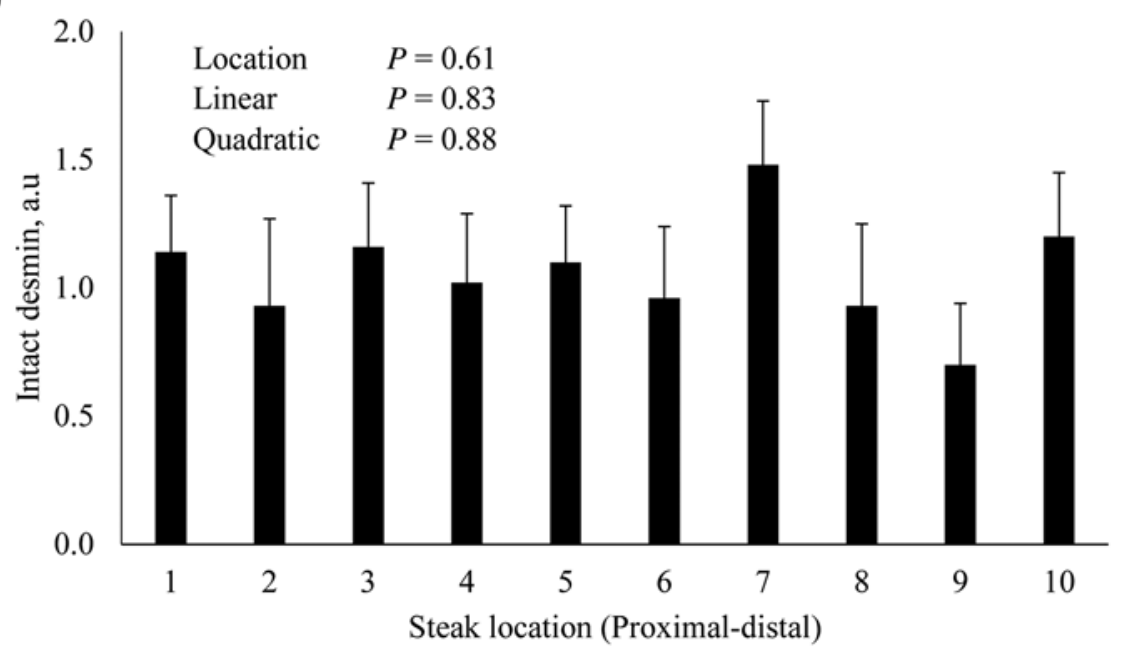

b)

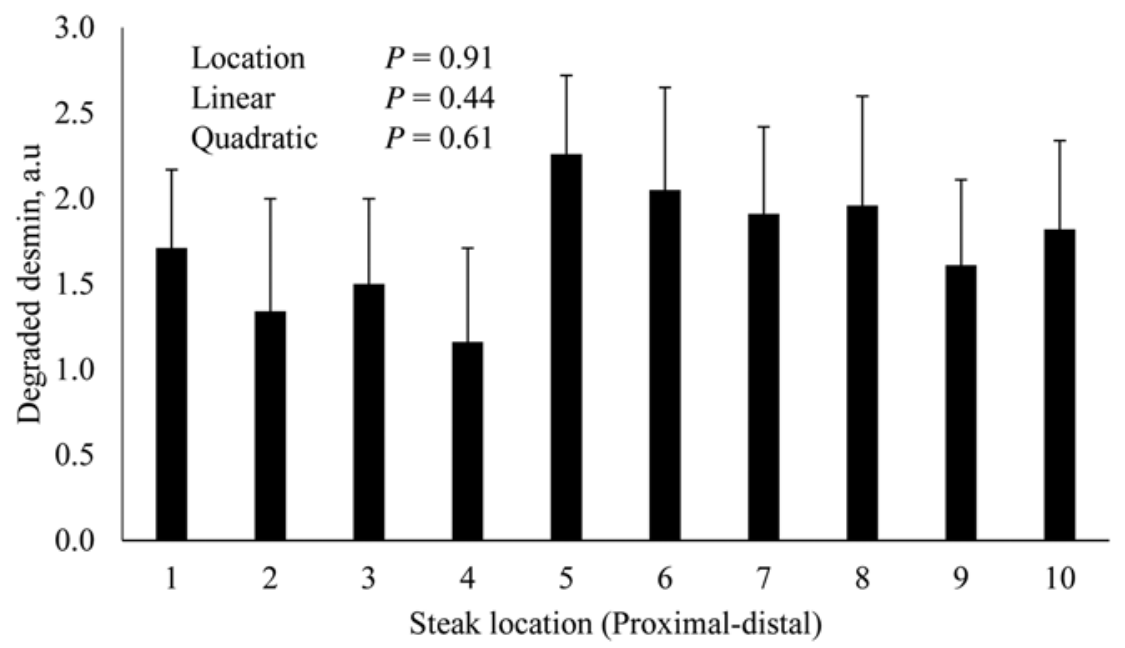

Figure 4. Effect of steak location on relative band densities of intact (a) and degraded (b) desmin of steaks fabricated from 10 distinct locations of the M. semitendinosus. Steak 1 is the most proximal to the carcass and steak 10 is the most distal to the carcass. Immunoreactive bands located at $55 \mathrm{kDa}$ and $38 \mathrm{kDa}$ were identified as the intact and degraded forms of desmin, respectively. Bands were equalized to a pooled sample on each blot.

cluding desmin and TnT (Huff-Lonergan et al., 1996). In accordance with past literature, the current study found that intact calpain-1 activity was greatest on $\mathrm{d} 7$, rapidly declined between $\mathrm{d} 7$ and 14 , and reductions in activity between the next 3 periods were smaller in magnitude until no activity was detected on d 70. Most literature indicates intact calpain-1 activity is diminished to zero by $\mathrm{d} 14$ or 21 of postmortem aging in beef (Boehm et al., 1998; Veiseth-Kent et al., 2010) and lamb (Delgado et al., 2001). In goat ST, Nagaraj et al. (2002) reported calpain-1 activity on d 20 postmortem had decreased by $98 \%$ of the d 0 postmortem activity. Geesink and Koohmaraie (1999b) reported that lamb M. biceps femoris intact calpain- 1 activity on 14 postmortem was $85 \%$ less than its activity on $\mathrm{d} 0$, and by $\mathrm{d} 56$ there was almost zero activity detected. In beef, Camou et al. (2007) reported intact calpain-1 activity decreased rapidly to almost zero by $\mathrm{d} 6$ postmortem in the M. longissimus thoracis, M. longissimus lumborum, M. semimembranosus, $\mathrm{M}$. triceps bra- chii, and M. psoas major. Interestingly, on d 42 of the current study samples from 11 of the $60(18 \%)$ steers still had calpain-1 activity. It is unknown why activity was still detected in these steers, but this finding certainly warrants further exploration.

A unique characteristic of the calpains is they undergo autolysis when activated; however, the autolyzed form of calpains still have some proteolytic activity, although this activity is quickly lost (Edmunds et al., 1991). The activity of autolyzed calpain-1 remained unchanged from $\mathrm{d} 7$ to 42 before decreasing at $\mathrm{d} 70$ postmortem. Utilizing an in vitro model, Geesink and Koohmaraie (1999a) reported almost all calpain-1 had autolyzed by $\mathrm{d} 1$, but the activity of the autolyzed form remained unchanged through $14 \mathrm{~d}$ postmortem and possibly caused the myofibrillar proteolysis they observed. When isolated from beef LM, Koohmaraie (1992a) observed autolyzed calpain-1 retained similar activity to intact calpain-1 during in vitro conditions. Calpain-2 activity 


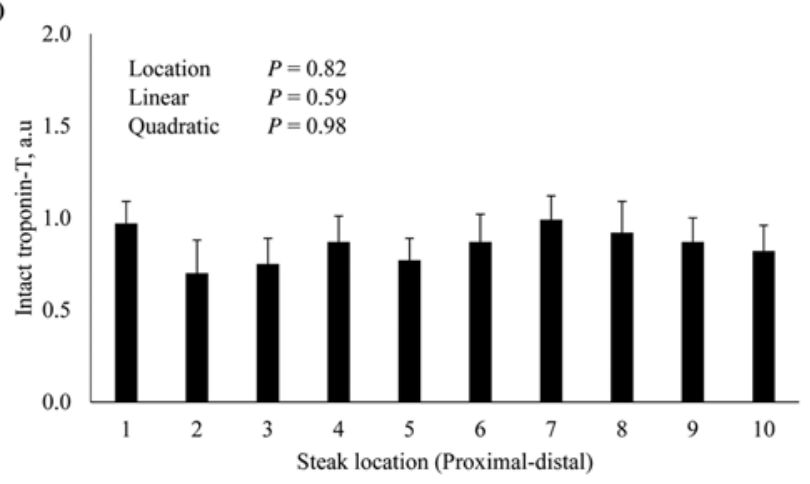

b)

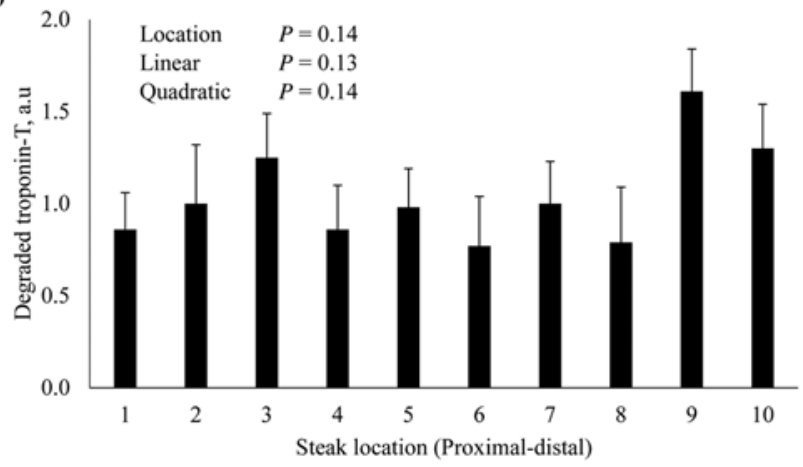

Figure 5. Effect of steak location on relative band densities of intact (a) and degraded (b) troponin-T of steaks fabricated from 10 distinct locations of the M. semitendinosus. Steak 1 is the most proximal to the carcass and steak 10 is the most distal to the carcass. Immunoreactive bands located at 40 and $30 \mathrm{kDa}$ were identified as intact and degraded forms of $\mathrm{TnT}$, respectively. Bands were equalized to a pooled sample on each blot.

increased during the aging period, peaking at $\mathrm{d} 42$ before decreasing sharply at $\mathrm{d} 70$. This pattern of activity was the main driver behind the shape of the total calpain activity response. Past literature indicates calpain-2 activity remains unchanged or slightly decreases with storage. In beef LM, Ducastaing et al. (1985) reported calpain-2 activity did not change during postmortem storage for 3 d. Similarly in lamb, Veiseth et al. (2001) reported calpain-2 activity of the LM remained unchanged during a 15 d postmortem period, and Geesink and Koohmaraie (1999b) reported calpain-2 activity remained unchanged in the M. bicep femoris through $56 \mathrm{~d}$ of postmortem aging. In contrast, Nagaraj et al. (2002) reported calpain-2 activity of the ST on d 20 postmortem had decreased $31 \%$ from the 0 postmortem activity. Similarly, Camou et al. (2007) reported a gradual decrease in calpain-2 activity from death until d 6 postmortem in beef M. longissimus thoracis, M. longissimus lumborum, M. semimembranosus, M. triceps brachii, and M. psoas major. Also, Boehm et al. (1998) reported calpain-2 activity of the M. semimembranosus at $\mathrm{d} 7$ postmortem decreased by $17 \%$ of the at-death activity. Because calpain- 1 activity was not detected past $42 \mathrm{~d}$ postmortem, it is plausible autolyzed calpain-1 and calpain-2 caused further proteolysis of desmin and TnT through d 70 .
The other component of this study was examining intramuscular tenderness differences of the ST and the causes of those differences. Previous literature reports tenderness gradients exist in the ST (Reuter et al., 2002; Senaratne et al., 2010). The differences in LOC tenderness of the ST in this study are similar to those reported previously. Shackelford et al. (1997) reported a similar pattern of shear force values within the ST, with steaks corresponding to steak 1 in the current study having an increased WBSF compared to steaks corresponding to locations 4 and 7, and steak 4 having a greater shear force than steak 7 . Also in accordance with the current study, Reuter et al. (2002) reported a quadratic type of tenderness gradient with steaks originating in the ends having greater shear force values than those from the middle. Rhee et al. (2004) selected 3 locations comparable to steak 1, steak 5, and steak 9 of the current study and found similar shear force value differences with steak 1 possessing greater WBSF than the other 2 steaks which were alike in WBSF value. Most recently, Senaratne et al. (2010) divided the ST into 12 different steaks and found a similar tenderness gradient to that reported by Reuter et al. (2002) and this study, with steaks originating from the ends of the muscle being tougher than those originating from the middle.

Ouali and Talmant (1990) reported beef muscles with a more oxidative fiber type (type I or IIA) possess more calpain-2 than beef muscles with a more glycolytic fiber type (type IIX). The authors hypothesized that calpain-1 was also most likely elevated given the constant calpain-1:calpain-2 ratio across muscles. Therefore, the proximal location should have possessed less calpain activity and degradation products since it contained almost $17 \%$ more type IIX fibers than the distal location. These expectations did not hold true since there were no differences in all variables examined, which indicated the tenderness differences of the locations are not due to postmortem enzymatic proteolysis. Rhee et al. (2004) found no differences in degraded desmin across 3 locations of the ST, but did report the steak with the greatest WBSF also had the shortest sarcomeres compared to the other 2 steak locations. This agrees with Locker (1960), who reported a strong relationship between sarcomere length and shear force. Although not measured in the current study, it is plausible there could be differences in sarcomere length across the ST which could contribute to differences in WBSF.

While sarcomere length was not measured, muscle fiber CSA, which is closely related to sarcomere length, was measured. In the current study, the proximal location had 33\% larger type I fibers, 24\% larger type IIA fibers, and 35\% larger type IIX fibers than distal muscle fibers. Research indicates larger muscle fibers are associated with increased shear force (Herring et al., 1965; Crouse 
a)

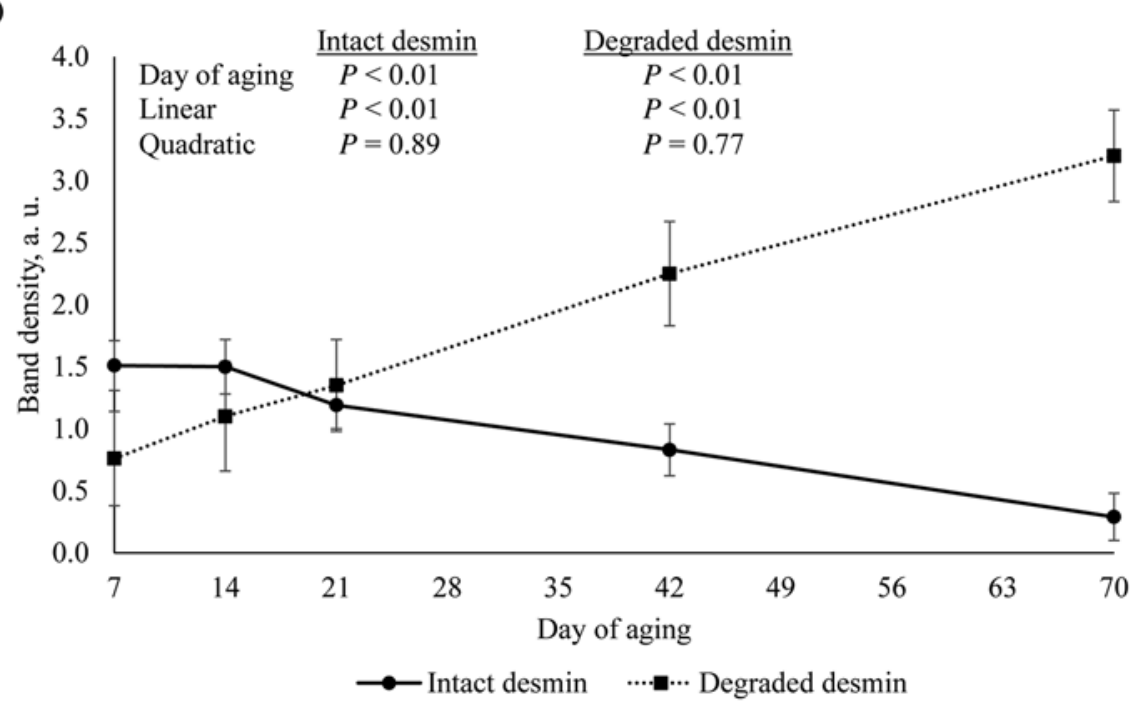

b)

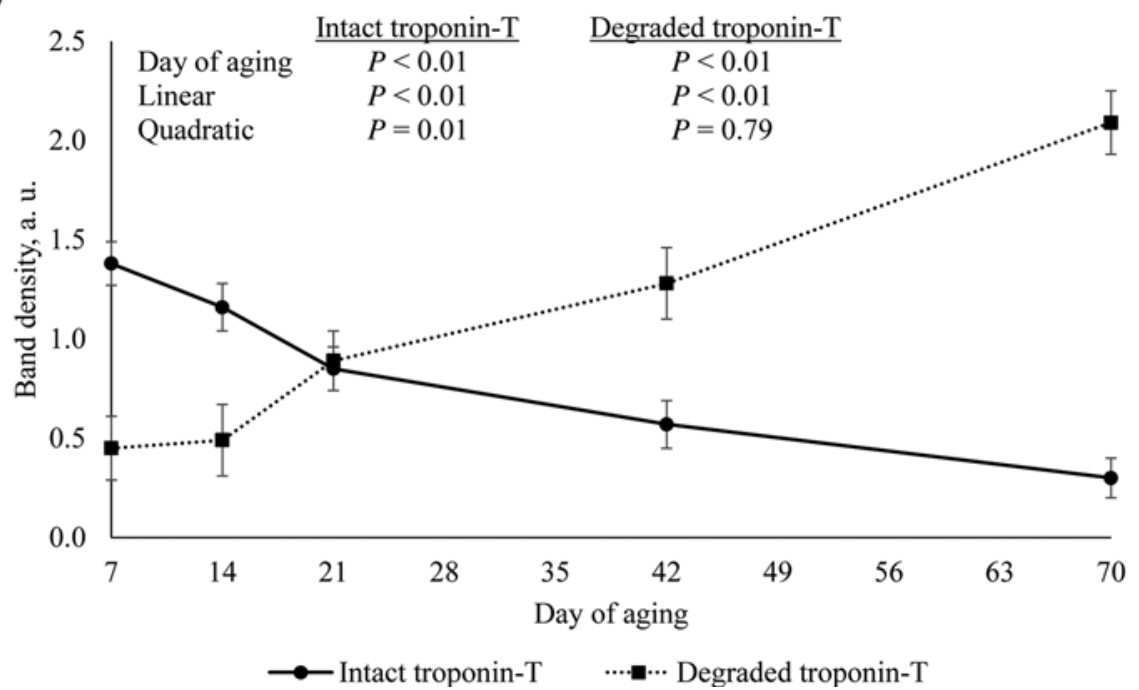

Figure 6. Effect of postmortem aging on relative band densities of intact and degraded desmin (a) and intact and degraded troponin-T (b) of M. semitendinosus steaks aged 7, 14, 21, 42, or $70 \mathrm{~d}$ postmortem. Immunoreactive bands located at $55 \mathrm{kDa}$ and $38 \mathrm{kDa}$ were identified as the intact and degraded forms of desmin, respectively. Immunoreactive bands located at 40 and $30 \mathrm{kDa}$ were identified as intact and degraded forms of TnT, respectively. Bands were equalized to a pooled sample on each blot.

et al., 1991; Renand et al., 2001). Ishii et al. (1995) collected muscle samples from the proximal, middle, and distal portions of the ST and reported CSA to be larger at the proximal and distal portions of the ST than the middle. In the current study, CSA of the middle portion of the muscle was not measured, so it is impossible to determine what effect muscle fiber CSA had on the decrease in WBSF as steaks were cut toward the middle of the muscle. Interestingly, steak 10 appears to have a smaller WBSF value than steak 1 . Since steaks 1 and 10 originated closest to the areas where the fiber type samples were taken, and there were drastic differences in muscle fiber CSA, the influence of fiber CSA on tenderness could explain the difference between the locations.

Besides degradation of the muscle fiber component of meat, the other major contributor to meat tenderness, connective tissue, could have influenced location WBSF.
Historical literature indicates the ST contains elevated levels of elastin compared to other muscles of the carcass (Bendall, 1967; Rowe, 1986). Rhee et al. (2004) found no differences in total collagen across 3 locations of the ST, but no other studies examine the intramuscular variation in ST connective tissue. Studies report collagen solubility rather than total collagen content influences WBSF (Stanton and Light 1987; Starkey et al., 2015). Collagen solubility is associated with the number of mature crosslinks, particularly hydryoxylysl pyridinoline (HP). Increased HP content can negatively impact WBSF (Lepetit, 2007). Steaks originating at the ends are likely to be more intricately linked with the tendons connecting the muscle to bone. Therefore, the collagen at these locations may turnover slower due to this association with the tendon and be more likely to form more of the insoluble HP crosslinks. Thus, if steaks originating 
a)

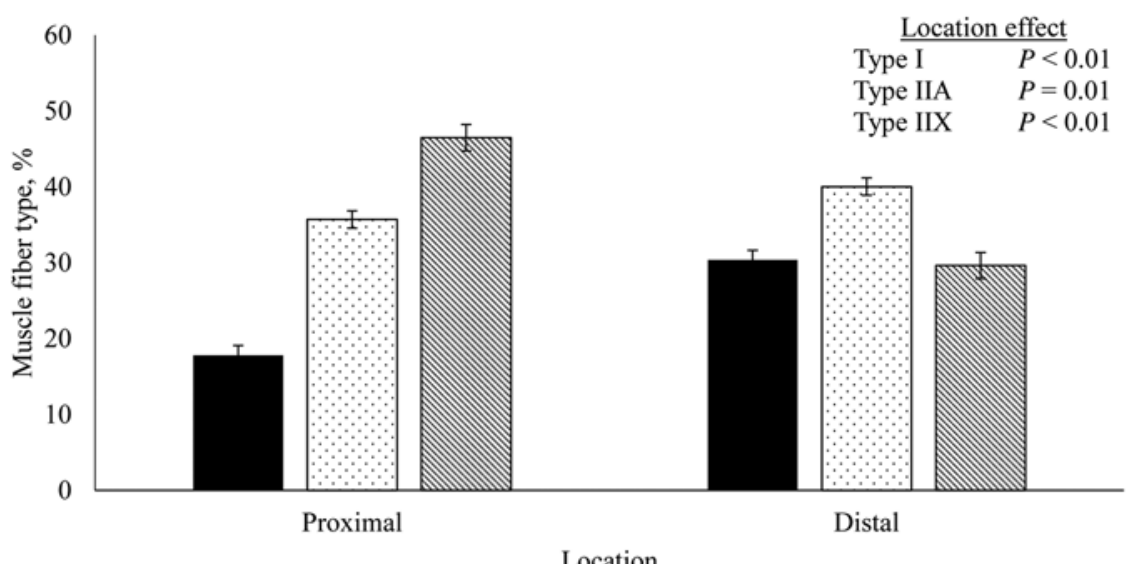

b)

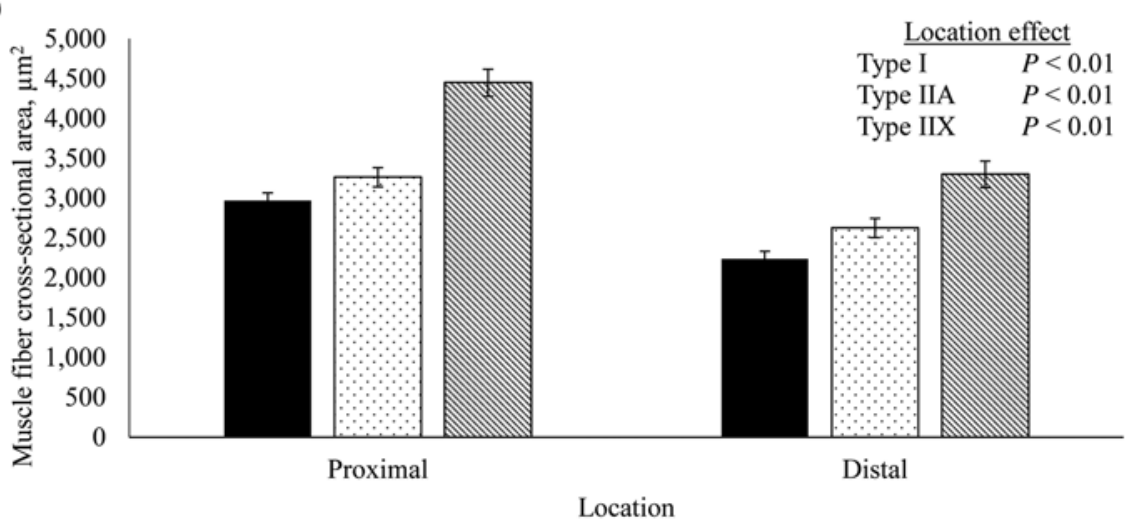

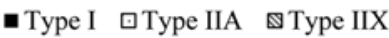

Figure 7. Muscle fiber type distribution (a) and cross-sectional area (b) of muscle fibers located at the proximal and distal ends of the M. semimembranosus muscle. The methods of Phelps et al. (2014) were followed for immunostaining and morphometric analysis.

from the ends have more HP this may explain observed WBSF differences, but this requires further exploration.

\section{Conclusions and Implications}

In agreement with previous literature, there were LOC differences in WBSF across the ST. There were no LOC differences in proteolytic activity and myofibrillar protein degradation patterns. These findings indicate that other tenderness influencers such as muscle fiber CSA, collagen solubility or cross-linking (Lepetit, 2007; Starkey et al., 2015), and/or degradation of the large structural proteins titin and nebulin (Huff-Lonergan et al., 1995) could be responsible for the location differences. Further research examining causes of intramuscular variations in tenderness of ST is warranted. Steaks fabricated from the ST continued to age through $70 \mathrm{~d}$ postmortem partly due to continued degradation of desmin and TnT. While intact calpain-1 activity ceased by d 42 postmortem, activity of calpain- 2 and autolyzed calpain-1 activity were reduced between d 42 and 70 postmortem, which may indicate they are responsible for continued tenderization of ST steaks. Further re- search is necessary to elucidate the cause of improved WBSF and increased myofibrillar degradation observed in extended postmortem aging of the ST.

\section{LITERATURE CITED}

AMSA. 2015. Research guidelines for cookery, sensory evaluation, and instrumental tenderness measurements of meat. Am. Meat Sci. Assoc., Champaign, IL.

ASTM. 2011. ASTM F 2925-11 Standard specification for tenderness marketing claims associated with meat cuts derived from beef. http://enterprise.astm.org/filtrexx40.cgi?+REDLINE_ PAGES/F2925.htm. (Accessed 22 February 2014.)

Beermann, D. H. 2009. ASAS centennial paper: A century of pioneers and progress in meat science in the United States leads to new frontiers. J. Anim. Sci. 87:1192-1198.

Bendall, J. R. 1967. Elastin content of various muscles of beef animals. J. Sci. Food Agric. 18:553-558.

Boehm, M. L., T. L. Kendall, V. F. Thompson, and D. E. Goll. 1998. Changes in the calpains and calpastatin during postmortem storage of bovine muscle. J. Anim. Sci. 76:2415-2434.

Camou, J. P., J. A. Marchello, V. F. Thompson, S. W. Mares, and D. E. Goll. 2007. Effect of postmortem storage on activity of $\mu$ - and $\mathrm{m}$ - calpain in five bovine muscles. J. Anim. Sci.

CCB. 2006. Industry guide for beef aging. Natl. Cattleman's Beef Assoc., Denver, CO. (Accessed 5 May 2015.) 
Crouse, J. D., M. Koohmaraie, and S. D. Seideman. 1991. The relationship of muscle fibre size to tenderness of beef. Meat Sci. 30:295-302.

Delgado, E. F., G. H. Geesink, J. A. Marchello, D. E. Goll, and M. Koohmaraie. 2001. The calpain system in three muscles of normal and callipyge sheep. J. Anim. Sci. 79:398-412.

Derington, A. J., J. C. Brooks, A. J. Garmyn, L. D. Thompson, D. B. Wester, and M. F. Miller. 2011. Relationships of slice shear force and Warner-Bratzler shear force of beef strip loin steaks as related to the tenderness gradient of the strip loin. Meat Sci. 88:203-208.

Dransfield, E. 1994. Optimisation of tenderization, ageing, and tenderness. Meat Sci. 36:105-121.

Ducastaing, A., C. Valin, J. Schollmeyer, and R. Cross. 1985. Effects of electrical stimulation on post-mortem changes in the activites of two $\mathrm{Ca}$ dependent neutral proteinases and their inhibitor in beef muscle. Meat Sci. 15:193-202.

Edmunds, T., P. A. Naginis, S. K. Sathe, V. F. Thompson, and D. E. Goll. 1991. Comparison of the autolyzed and unautolyzed forms of mu- and m- calpain from bovine skeletal muscle. Biochim. Biophys. Acta 1077:197-208.

Geesink, G. H., and M. Koohmaraie. 1999a. Effect of calpastatin on degradation of myofibrillar proteins by $\mu$-calpain under postmortem conditions. J. Anim. Sci. 77:2685-2692.

Geesink, G. H., and M. Koohmaraie. 1999b. Postmortem proteolysis and calpain/calpastatin activity in callipyge and normal lamb biceps femoris during extended postmortem storage. J. Anim. Sci. 77:1490-1501.

Gruber, S. L., J. D. Tatum, J. A. Scanga, P. L. Chapman, G. C. Smith, and K. E. Belk. 2006. Effects of postmortem aging and USDA quality grade on Warner-Bratzler shear force values of seventeen individual beef muscles. J. Anim. Sci. 84:3387-3396.

Guelker, M. R., A. N. Haneklaus, J. C. Brooks, C. C. Carr, R. J. Delmore, Jr., D. B. Griffin, D. S. Hale, K. B. Harris, G. G. Mafi, D. D. Johnson, C. L. Lorenzen, R. J. Maddock, J. N. Martin, R. K. Miller, C. R. Raines, D. L. Van Overbeke, L. L. Vedral, B. E. Wasser, and J. W. Savell. 2013. National Beef Tenderness Survey-2010: Warner-Bratzler shear force values and sensory panel ratings for beef steaks from United States retail and food service establishments. J. Anim. Sci. 91:1005-1014.

Herring, H. K., R. G. Cassens, and E. J. Rriskey. 1965. Further studies on bovine muscle tenderness as influenced by carcass position, sarcomere length, and fiber diameter. J. Food Sci. 30:1049-1054.

Huff-Lonergan, E., T. Mitsuhashi, D. D. Beekman, F. C. Parrish, Jr., D. G. Olson, and R. M. Robson. 1996. Proteolysis of specific muscle structural proteins by $\mu$-calpain at low $\mathrm{pH}$ and temperature is similar to degradation in postmortem bovine muscle. J. Anim. Sci. 74:993-1008.

Huff-Lonergan, E., F. C. Parrish, and R. M. Robson. 1995. Effects of postmortem aging time, animal age, and sex on degradation of titin and nebulin in bovine longissimus muscle. J. Anim. 73:1064-1073.

Huff-Lonergan, E., W. Zhang, and S. M. Lonergan. 2010. Biochemistry of postmortem muscle- Lessons on mechanisms of meat tenderization. Meat Sci. 86:184-195.

Igo, J. L., D. L. VanOverbeke, D. R. Woerner, J. D. Tatum, D. L. Pendell, L. L. Vedral, G. G. Mafi, M. C. Moore, R. O. McKeith, G. D. Gray, D. B. Griffin, D. S. Hale, J. W. Savell, and K. E. Belk. 2013. Phase I of The National Beef Quality Audit-2011: Quantifying willingness-to-pay, best-worst scaling, and current status of quality characteristics in different beef industry marketing sectors. J. Anim. Sci. 91:1907-1919.
Ishii, T., H. Kiyohara, K. Mitani, and H. Miyamoto. 1995. Variance of cross-sectional areas of muscle fibers among sampling positions in skeletal muscles of cattle. Anim. Sci. Technol. (Jpn.) 66:399-405.

Juarez, M., I. L. Larsen, L. L. Gibson, W. M. Robertson, M. E. R. Dugan, N. Aldai, and J. L. Aalhus. 2010. Extended ageing time and temperature effects on quality of sub-primal cuts of boxed beef. Can. J. Anim. Sci. 90:361-370.

Kemp, C. M., P. L. Sensky, R. G. Bardsley, P. J. Buttery, and T. Parr. 2010. Tenderness-An enzymatic view. Meat Sci. 84:248-256.

Kerth, C. R., J. L. Montgomery, J. L. Lansdell, C. B. Ramsey, and M. F. Miller. 2002. Shear gradient in longissimus steaks. J. Anim. Sci. 80:2390-2395.

Koohmaraie, M. 1992a. Effect of pH, temperature, and inhibitors on autolysis and catalytic activity of bovine skeletal muscle $\mu$-calpain. J. Anim. Sci. 70:3071-3080.

Koohmaraie, M. 1992b. Ovine skeletal muscle multicatalytic proteinase complex (proteasome): Purification, characterization, and comparison of its effects on myofibrils with $\mu$-calpains. J. Anim. Sci. 70:3697-3708.

Koohmaraie, M. 1994. Muscle proteinases and meat aging. Meat Sci. 36:93-104.

Koohmaraie, M., and G. H. Geesink. 2006. Contribution of postmortem muscle biochemistry to the delivery of consistent meat quality with particular focus on the calpain system. Meat Sci. 74:34 43 .

Lehman, K. B. 1907. Studies of the causes for the toughness of meat. Arch. Hyg. 63:134.

Lepetit, J. 2007. A theoretical approach of the relationships between collagen content, collagen cross-links and meat tenderness. Meat Sci. 76:147-159.

Light, N., A. E. Champion, C. Voyle, and A. J. Bailey. 1985. The of epimysial, perimysial and endomysial collagen in determining texture in 6 bovine muscles. Meat Sci. 13:137-149.

Locker, R. H. 1960. Degree of muscular contraction as a factor in tenderness of beef. J. Food Sci. 25:304-307.

Lonergan, S. M., E. Huff-Lonergan, L. J. Rowe, D. L. Kuhlers, and S. B. Jungst. 2001. Selection for lean growth efficiency in Duroc pigs influences pork quality. J. Anim. Sci. 79:2075-2085.

Lusk, J. L., J. A. Fox, T. C. Schroeder, J. Mintert, and M. Koohmaraie. 2001. In-store valuation of steak tenderness. Am. J. Agric. Econ. 83:539-550.

Marino, R., A. della Malva, and M. Albenzio. 2015. Proteolytic changes of myofibrillar proteins in Podolian meat during aging: Focusing on tenderness. J. Anim. Sci. 93:1376-1387.

Melody, J. L., S. M. Lonergan, L. J. Rowe, T. W. Huiatt, M. S. Mayes, and E. Huff-Lonergan. 2004. Early postmortem biochemical factor influence tenderness and water-holding capacity of three porcine muscles. J. Anim. Sci. 82:1195-1205.

Miller, M. F., M. A. Carr, C. B. Ramsey, K. L. Crockett, and L. C. Hoover. 2001. Consumer thresholds for establishing the value of beef tenderness. J. Anim. Sci. 79:3062-3068.

Moreno-Sanchez, N., C. Diaz, M. J. Carabano, J. Rueda, and J. L. Rivero. 2008. A comprehensive characterization of the fibre composition and properties of a limb (Flexor digitorum superficialis, membri thoraci) and a trunk (Psoas major) muscle in cattle. BMC Cell Biol. 9:67.

Nagaraj, N. S., K. R. Anilakumar, and K. Santhanam. 2002. Changes in the calpain-calpastatin and cathepsin $(\mathrm{B}, \mathrm{B}+\mathrm{L}, \mathrm{H}$ and $\mathrm{D})$ during postmortem storage of goat muscles. J. Food Biochem. 26:75-89.

Ouali, A., C. H. Herrera-Mendez, G. Coulis, S. Becila, A. Boudjellal, L. Aubry, and M. A. Senandreu. 2006. Revisiting the conversion of muscle to meat and the underlying mechanisms. Meat Sci. 74:44-58. 
Ouali, A., and A. Talmant. 1990. Calpains and calpastatin distribution in bovine, porcine, and ovine skeletal-muscles. Meat Sci. 28:331-348.

Phelps, K. J., J. S. Drouillard, J. S. Jennings, C. L. Van BibberKrueger, K. A. Miller, M. A. Vaughn, D. D. Burnett, S. M. Ebarb, T. A. Houser, S. E. Johnson, and J. M. Gonzalez. 2014. Effects of the Programmed Nutrition Beef Program on meat quality characteristic. J. Anim. Sci. 92:1780-1792.

Purslow, P. P. 2005. Intramuscular connective tissue and its role in meat quality. Meat Sci. 70:435-447. doi:10.1016/j.meatsci. 2004.06.028.

Renand, G., B. Picard, C. Touraille, P. Berge, and J. Lepetit. 2001. Relationships between muscle characteristics and meat quality traits of young Charolais bulls. Meat Sci. 59:49-60.

Reuter, B. J., D. M. Wulf, and R. J. Maddock. 2002. Mapping intramuscular tenderness variation in four major muscles of the beef round. J. Anim. Sci. 80:2594-2599.

Rhee, M. S., T. L. Wheeler, S. D. Shackelford, and M. Koohmaraie. 2004. Variation in palatability and biochemical traits within and among eleven beef muscles. J. Anim. Sci. 82:534-500.

Rowe, R. W. D. 1986. Elastin in bovine semitendinosus and longissimus dorsi muscles. Meat Sci. 17:293-312.

Schiaffino, S., L. Gorza, S. Sartore, L. Saggin, S. Ausoni, M. Vianello, K. Gundersen, and T. Lomo. 1989. Three myosin heavy chain isoforms in type 2 skeletal muscle fibres. J. Muscle Res. Cell Motil. 10:197-205.

Senaratne, L. S., C. R. Calkins, A. S. de Mello, Jr., S. Pokharel, and J. B. Hinkle. 2010. Mapping of intramuscular tenderness and muscle fiber orientation of muscle in the beef round. J. Anim. Sci. 88:3084-3106.
Sentandreu, M. A., G. Coulis, and A. Ouali. 2002. Role of muscle endopeptidases and their inhibitors in meat tenderness. Trends Food Sci. Technol. 13:400-421.

Shackelford, S. D., M. Koohmaraie, L. V. Cundiff, K. E. Gregory, G. A. Rohrer, and J. W. Savell. 1994. Heritabilities and phenotypic and genetic correlations for bovine postrigor calpastatin activity, intramuscular fat content, Warner-Bratzler shear force, retail product yield, and growth rate. J. Anim. Sci. 72:857-863.

Shackelford, S. D., T. L. Wheeler, and M. Koohmaraie. 1997. Repeatability of tenderness measurements in beef round muscles. J. Anim. Sci. 75:2411-2416.

Stanton, C., and N. Light. 1987. The effects of conditioning on meat collagen. 1. Evidence for gross in situ proteolysis. Meat Sci. 21:249-265.

Starkey, C. P., G. H. Geesink, V. H. Oddy, and D. L. Hopkins. 2015. Explaining the variation in lamb longissimus shear force across and within ageing periods using protein degradation, sarcomere length, and collagen characteristics. Meat Sci. 105:32-37.

Veiseth, E., S. D. Shackelford, T. L. Wheeler, and M. Koohmaraie. 2001. Effect of postmortem storage on $\mu$-calpain and m-calpain in ovine skeletal muscle. J. Anim. Sci. 79:1502-1508.

Veiseth-Kent, E., K. Hollung, R. Ofstad, L. Aass, and K. I. Hildrum. 2010. Relationship between muscle microstructure, the calpain system, and shear force in bovine longissimus dorsi muscle. J. Anim. Sci. 88:3445-3451.

Von Seggern, D. D., C. R. Calkins, D. D. Johnson, J. E. Brickler, and B. L. Gwartney. 2005. Muscle profiling: Characterizing the muscles of the beef chuck and round. Meat Sci. 71:39-51. . 